\title{
Reduction of lead and zinc sulphates by hydrogen
}

\author{
Stanisław Małecki ${ }^{1}$
}

Received: 8 January 2015/Accepted: 3 March 2015/Published online: 18 March 2015

(C) The Author(s) 2015. This article is published with open access at Springerlink.com

\begin{abstract}
In this paper, the results of the thermogravimetric tests reduction of lead and zinc sulphates by hydrogen are presented. Tests performed under isothermal conditions allowed to determine the effect of temperature on the formed products of the reaction. The temperatures at which the maximum content of sulphides present in the products of reduction were determined. For the reduction of lead sulphate, value of the activation energy of the process and the participation of partial reactions in the process were determined.
\end{abstract}

Keywords Reduction by hydrogen $\cdot$ Lead sulphate $\cdot$ Zinc sulphate $\cdot$ Thermogravimetric analysis $\cdot$ Kinetics

\section{Introduction}

This paper represents a fragment of the research on the reduction of metal sulphates. In the literature, the problem of thermal reduction of metal sulphates is quite simply treated. Research using $\mathrm{CO}$ for the reduction is presented only by the authors [1]. They concern the reduction of magnesium sulphate. The results of the metal sulphates reduction by hydrogen were presented in the papers [2,3]. The authors indicate the reduction temperature range and products obtained in these temperatures. However, these results are rather qualitative, without going into the chemical and phase composition of the process products. Vijh [4] presents an

Stanisław Małecki

stanmal@agh.edu.pl

1 Faculty of Non-Ferrous Metals, AGH University of Science and Technology, 30 Mickiewicza Av., 30-059 Kraków, Poland analysis of the sulphate reduction temperature dependence of the selected physicochemical parameters.

The study presented here is a continuation of the study of the reduction of the lead sulphate. The results of the previous study [5] concerning the reduction of lead sulphate $\mathrm{PbSO}_{4}$ by $\mathrm{CO}$ show that the first process is the formation of lead sulphide which then reacts at the interface of the phases with the sulphate. The range of the temperatures (893$1073 \mathrm{~K}$ ) for which the lead sulphate reduction was conducted suggests that for the reaction between the original product, i.e. $\mathrm{PbS}$, and $\mathrm{PbSO}_{4}$, a basic lead sulphate $\mathrm{PbO} \cdot \mathrm{PbSO}_{4}$ should be formed [6]. Then, this product will undergo further reduction, and as a result, the metallic lead and lead sulphide will be formed. Therefore, the reaction scheme of this process will have the following form:

$\mathrm{PbSO}_{4} \rightarrow \mathrm{PbS}, \mathrm{PbSO}_{4} \rightarrow \mathrm{PbO} \cdot \mathrm{PbSO}_{4} \rightarrow \mathrm{Pb}, \mathrm{PbS}$

Continuation of research on the reduction of basic lead sulphate is shown in Małecki [7].

This work relates to the research on the reduction of lead sulphate $\mathrm{PbSO}_{4}$ and zinc sulphate $\mathrm{ZnSO}_{4}$ in a hydrogen atmosphere under isothermal conditions. The applied thermogravimetric method allowed us to perform calculations of phase composition of the reaction products and determine the contribution of each simple reaction in the whole process. This made it possible to determine the temperatures at which in the products is formed the largest amount of sulphides.

\section{Methodology of the study}

For the research, were used lead and zinc sulphates of analytical grade. Zinc sulphate contains 7 water molecules, and before the reduction, the process was subjected to 
dehydration at a temperature of $723 \mathrm{~K}$. Preliminary investigations carried out with increasing temperature allowed us to determine the temperature range for isothermal measurements. They have been defined the temperature range for the lead sulphate at $873-973 \mathrm{~K}$, and for zinc sulphate at 853-973 K.

Investigations on reduction of lead and zinc sulphates were carried out by thermogravimetry method using Thermal Analyzer TA-1 Mettler. A sample of defined mass is placed in a furnace through which flowed hydrogen at the amount of $15 \mathrm{dm}^{3} \mathrm{~h}^{-1}$. The stream of flowing hydrogen was selected so that it did not affect the process rate. The temperature in the furnace was controlled by a Pt$\mathrm{RhPt}$ thermocouple placed directly underneath the tested sample. The sample was heated to isothermal temperature with rate of $25^{\circ} \mathrm{min}^{-1}$. During the process, the sample mass change was recorded over time. Masses of sulphate samples were practically identical for each temperature measurement and amounted approximately $300 \mathrm{mg}$. Process time was measured from the moment of insertion of the sample into the furnace to establishment of a constant mass. Each measurement was repeated three times, and the results were averaged.

The recorded mass losses indicate that in the case of lead sulphate reduction, the total sample mass change is between the values of the reaction course from lead sulphide to lead metal, whereas the mass loss of the zinc sulphate reduction is between the values of the reaction course from zinc sulphide to zinc oxide. In the first case, phase analysis indicated only the occurrence of lead sulphide and metallic lead in products, while in the second case zinc sulphide and zinc oxide.

\section{Analysis of the experimental results}

\section{Lead sulphate reduction}

The change in sample mass recorded at the time of measurements allowed us to determine the relative mass loss of the samples after a specified time of the experiment. Results obtained from the calculation are shown in Fig. 1. Due to the fact that the X-ray phase analysis showed only the occurrence of lead sulphide and metallic lead in reaction products, the relative mass loss in case if the products contain only $\mathrm{PbS}$ or only metallic lead was marked by solid lines in the figure.

The presented dependency shows significant effects of temperature on the rate of lead sulphate reduction process. At maximum rates of the process, the temperature change of $25^{\circ}$ causes a twofold increase in the relative mass loss of the sample. Because in every temperature the process was carried out to obtain a constant mass, it is possible to

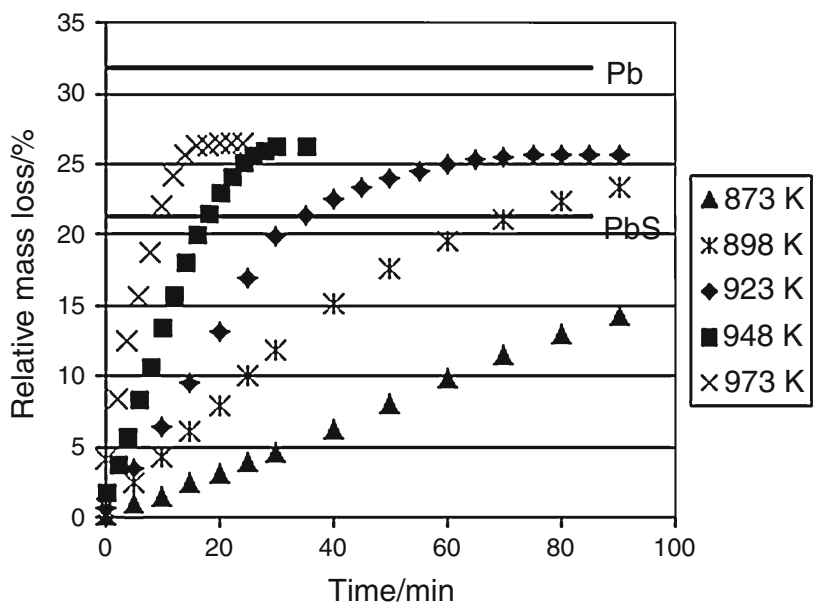

Fig. 1 Change in the relative mass loss of the $\mathrm{PbSO}_{4}$ sample during the process of reduction by hydrogen in different temperatures

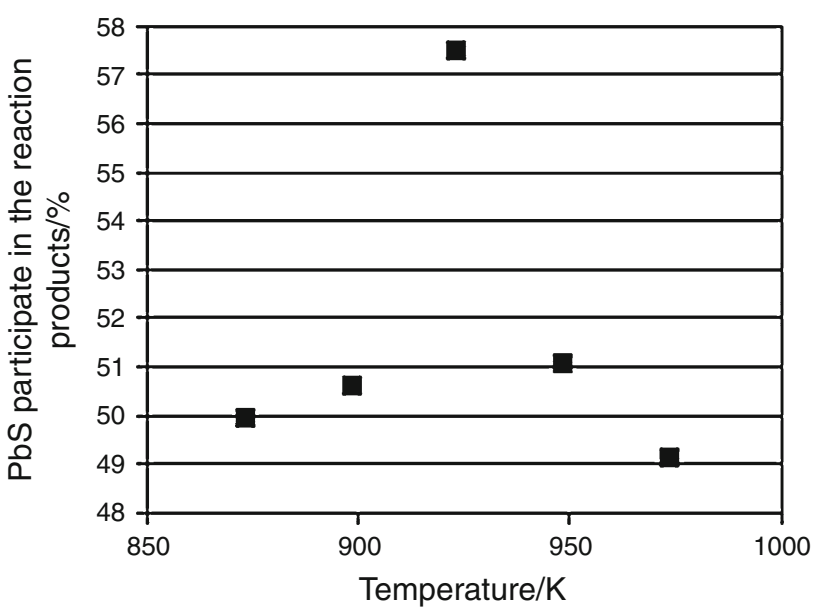

Fig. 2 Relationship between the lead sulphide content in the products as a function of temperature

determine the maximum mass change for each temperature. These results are located within a relatively narrow range of $25.5-26.5 \%$, but they show a clear trend confirmed by repeated measurements at the same temperatures. This translates directly to the amount of $\mathrm{PbS}$ and $\mathrm{Pb}$ in the reaction products. This dependence for the $\mathrm{PbS}$ participation in products is shown in Fig. 2.

The percentage of $\mathrm{PbS}$ in products was calculated from the relationship:

$\% \mathrm{PbS}=\frac{\left(\frac{\Delta m_{\mathrm{t}}}{m_{\mathrm{PbS}}^{\circ}}\right)_{\mathrm{PbSO}_{4} \rightarrow \mathrm{Pb}}-\frac{\Delta m_{\mathrm{p}}}{m_{\mathrm{o}}}-\left(\frac{\Delta m_{\mathrm{t}}}{m_{\mathrm{PbO}}^{o}}\right)_{\mathrm{PbO} \rightarrow \mathrm{Pb}}}{\left(\frac{\Delta m_{\mathrm{t}}}{m_{\mathrm{PbSO}_{4}}^{\mathrm{o}}}\right)_{\mathrm{PbSO}_{4} \rightarrow \mathrm{Pb}}+\left(\frac{\Delta m_{\mathrm{t}}}{m_{\mathrm{PbO}}^{\circ}}\right)_{\mathrm{PbO} \rightarrow \mathrm{Pb}}-\left(\frac{\Delta m_{\mathrm{t}}}{m_{\mathrm{PbSO}_{4}}^{\circ}}\right)_{\mathrm{PbSO}_{4} \rightarrow \mathrm{PbS}}} \times 100$ 
where $\left(\frac{\Delta m_{\mathrm{t}}}{m_{\mathrm{PbSO}_{4}}^{\mathrm{o}}}\right)_{\mathrm{PbSO}_{4} \rightarrow \mathrm{Pb}}$-the relative mass loss of the sample corresponding to the transformation $\mathrm{PbSO}_{4}$ to $\mathrm{Pb}$, $\frac{\Delta m_{\mathrm{p}}}{m_{\mathrm{o}}}$ - the relative mass loss of the sample, $\left(\frac{\Delta m_{\mathrm{t}}}{m_{\mathrm{PbO}}^{\circ}}\right)_{\mathrm{PbO} \rightarrow \mathrm{Pb}}-$ the relative mass loss of the sample corresponding to the transformation $\mathrm{PbO}$ to $\mathrm{Pb},\left(\frac{\Delta m_{\mathrm{t}}}{m_{\mathrm{PbSO}_{4}}^{\circ}}\right)_{\mathrm{PbSO}_{4} \rightarrow \mathrm{PbS}}$-the relative mass loss of the sample corresponding to the transformation $\mathrm{PbSO}_{4}$ to $\mathrm{PbS}$.

This dependence implies that the largest quantities of lead sulphide are obtained at $923 \mathrm{~K}$, and both above and below this temperature the amount of metallic lead obtained increases. It is worth noting that in triplicate measurement for the same isothermal temperature obtained, values of relative mass loss differed by $\pm 0.1 \%$. Thus, differences in the maximum mass loss do not arise from measurement errors, but only from the result of the reaction occurring during the process. Character of the relationship results from a series of simultaneously running reactions. Due to the variation of their rate under certain temperature conditions, which also depends on the ratio of substrates, their cumulative effect is so different. A slightly different character of similar correlations was obtained for reduction of $\mathrm{PbSO}_{4}$ by $\mathrm{CO}$ [4]. In this case, a greater difference is noted in the mass loss of samples, and therefore greater differences in the amounts of the various reaction products.

Table $1 \mathrm{PbSO}_{4}$ distribution on the individual reactions at different temperatures of the process

\begin{tabular}{llll}
\hline $\begin{array}{l}\text { Process } \\
\text { temperature/K }\end{array}$ & \begin{tabular}{l}
$\mathrm{PbSO}_{4}$ distribution/\% \\
\cline { 2 - 4 }
\end{tabular} & $\begin{array}{l}\mathrm{PbSO}_{4}+4 \mathrm{H}_{2} \\
\mathrm{PbS}+4 \mathrm{H}_{2} \mathrm{O}\end{array}$ & $\begin{array}{l}3 \mathrm{PbO}_{4} \\
+\mathrm{PbS}=4 \mathrm{PbO} \\
+4 \mathrm{SO}_{2}\end{array}$
\end{tabular}

Additionally, with decrease in the proportion of $\mathrm{CO}$ in the gaseous phase, only metallic lead can be obtained.

In the following discussion, it was assumed that in the system run the following reactions:

$\mathrm{PbSO}_{4}+4 \mathrm{H}_{2}=\mathrm{PbS}+4 \mathrm{H}_{2} \mathrm{O}$

$3 \mathrm{PbSO}_{4}+\mathrm{PbS}=4 \mathrm{PbO}+4 \mathrm{SO}_{2}$

$\mathrm{PbO}+\mathrm{H}_{2}=\mathrm{Pb}+\mathrm{H}_{2} \mathrm{O}$

Due to the presence of the reducer and experimental temperatures, the following reaction was not taken into account

$2 \mathrm{PbO}+\mathrm{PbS}=3 \mathrm{~Pb}+\mathrm{SO}_{2}$

Assuming such course of processes, with the knowledge of the products composition resulting from the sample mass loss during the process, we can calculate the distribution of $\mathrm{PbSO}_{4}$ on the individual reactions. The calculated values are presented in Table 1 . These indicate that the reduction of sulphate to sulphide rises up to the temperature of $923 \mathrm{~K}$ and decreases thereafter. Unreacted amount of lead sulphate calculated from the difference in mass balance is about $1 \%$.

Continuing the calculation can determine the contribution of individual reactions (3)-(5) in the total mass loss of the sample. These results are shown in Table 2. With these data, and assuming that the rate of reaction progress is not altered during the process, the kinetic curves of the individual partial reactions were determined. They are presented in Figs. 3-5.

Relationships with these drawings show how the contribution of each reaction changes depending on the process temperature. The highest participation of reduction reaction of sulphate to sulphide at a temperature of $923 \mathrm{~K}$ may indicate the highest rate of the reaction under these conditions. Decreasing participation of sulphate reduction reaction at higher temperatures may indicate a significant increase in the rate of secondary reactions, in particular the reaction between lead sulphide and sulphate.

The total conversion degrees were used to determine the kinetic equation describing the process. The calculations were performed for different kinetic equations [8, 9]. The

Table 2 Contribution of individual reactions in the total mass loss for the different temperatures of the process

\begin{tabular}{llll}
\hline Process temperature/K & \multicolumn{3}{l}{ Participation in the total mass loss/\% } \\
\cline { 2 - 4 } & $\mathrm{PbSO}_{4}+4 \mathrm{H}_{2}=\mathrm{PbS}+4 \mathrm{H}_{2} \mathrm{O}$ & $3 \mathrm{PbSO}_{4}+\mathrm{PbS}=4 \mathrm{PbO}+4 \mathrm{SO}_{2}$ & $\mathrm{PbO}^{2} \mathrm{H}_{2}=\mathrm{Pb}+\mathrm{H}_{2} \mathrm{O}$ \\
\hline 873 & 47.74 & 41.81 & 10.45 \\
898 & 48.29 & 41.37 & 10.34 \\
923 & 53.95 & 36.84 & 9.21 \\
948 & 48.65 & 41.08 & 10.27 \\
973 & 47.13 & 42.29 & 10.57 \\
\hline
\end{tabular}




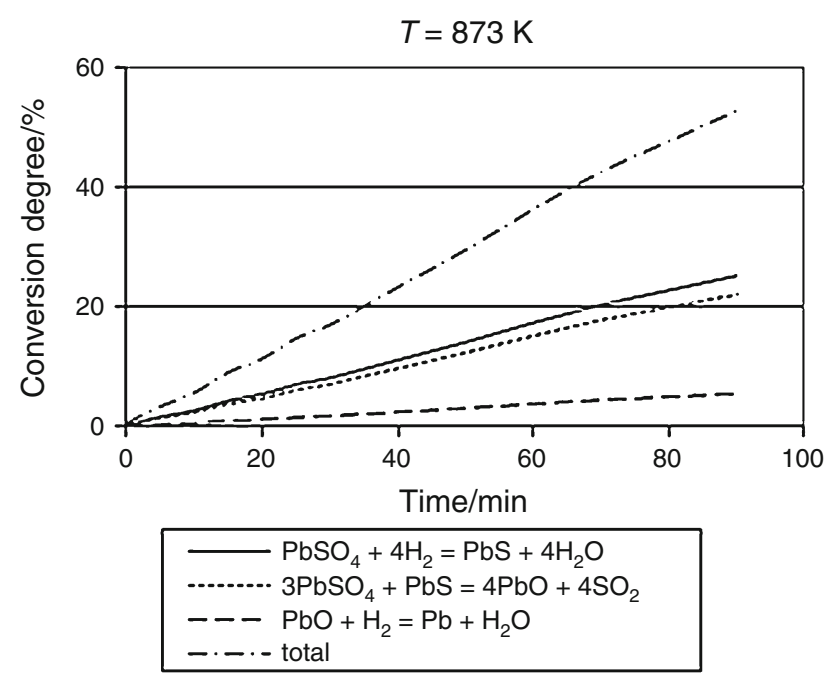

Fig. 3 Kinetic curves for a particular reaction for the temperature $873 \mathrm{~K}$

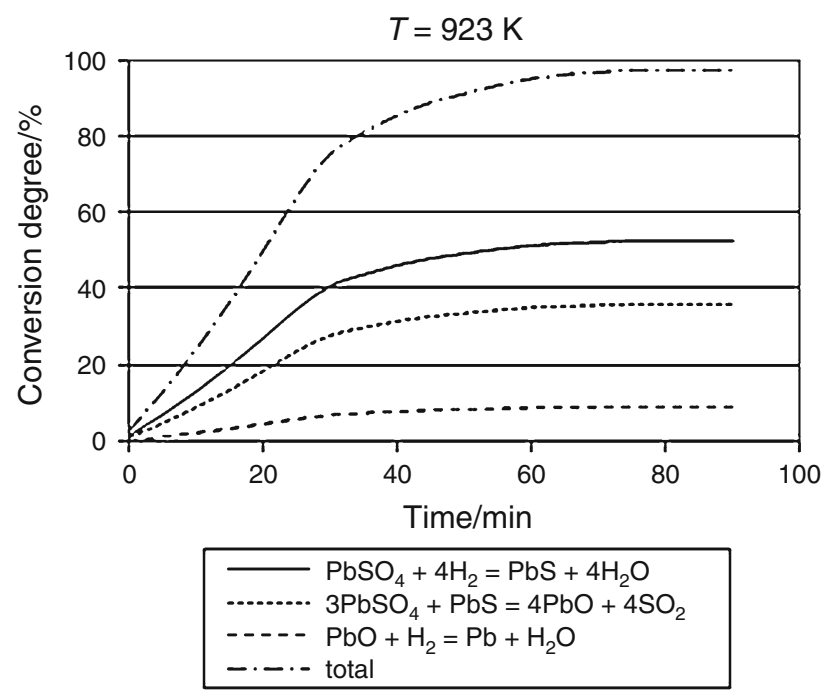

Fig. 4 Kinetic curves for a particular reaction for the temperature $923 \mathrm{~K}$

best fit of the experimental data was obtained for the equation in the form [9]:

$1-(1-\alpha)^{\frac{2}{3}}=k \cdot t+A$

where $\alpha$-degree conversion, $k$-constant proportional to the reaction rate, $t$-process duration, $A$-initial ordinate.

The process of calculated regression equations on background experimental points for different temperatures of the process is shown in Fig. 6. In Table 3, the compilation of the values of kinetic equations parameters for various process conditions is given.

Designated equations were used to determine the activation energy of the process. The calculated value is $181.1 \pm 9.5 \mathrm{~kJ} \mathrm{~mol}^{-1}$.

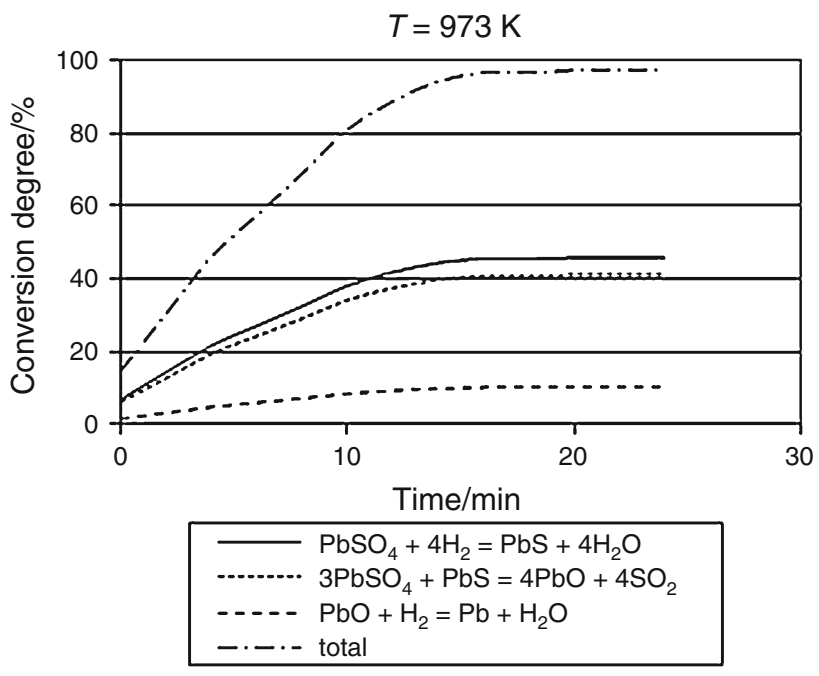

Fig. 5 Kinetic curves for a particular reaction for the temperature $973 \mathrm{~K}$

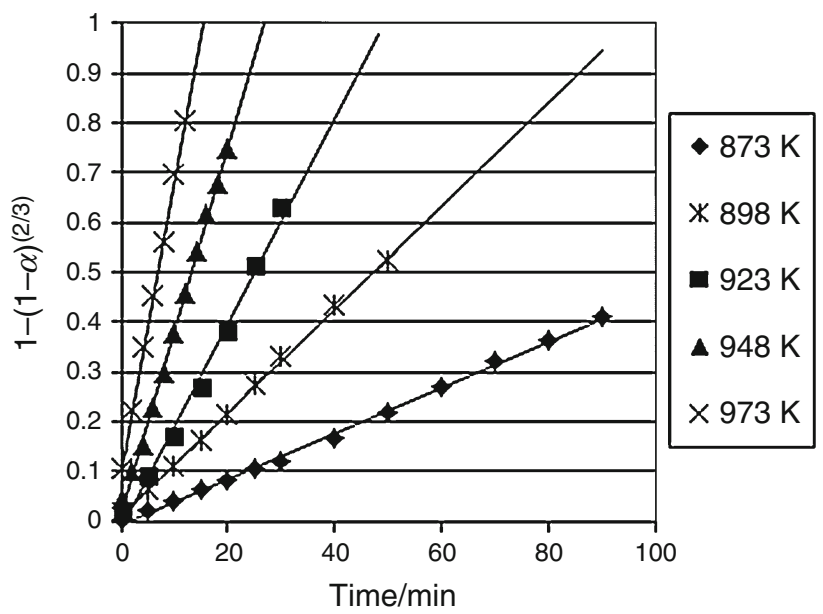

Fig. 6 Course of kinetic equations on background experimental points for the $\mathrm{PbSO}_{4}$ reduction by hydrogen at different process temperatures

\section{Zinc sulphate reduction}

Zinc sulphate reduction process was carried out in the temperature range at which there are no zinc oxide reduction processes or reaction between the sulphide and zinc oxide. In the reaction products after the process zinc sulphide and zinc oxide is detectable, occurring in varying proportions depending on the process temperature. The procedure for the analysis of experimental data was similar to that in the case of lead sulphate reduction. The data of the sample mass change were used to calculate the relative mass loss after a specified duration of the process. These results are presented in Fig. 7.

The relationships shown in Fig. 7 indicate a complicated course of the zinc sulphate reduction process. In the curves, 
Table 3 Values of the parameters of the kinetic equation for $\mathrm{PbSO}_{4}$ reduction

\begin{tabular}{llcl}
\hline Temperature/K & $\begin{array}{l}\text { Constant } \\
\mathrm{k} / \mathrm{s}^{-1}\end{array}$ & Starting ordinate A & $\begin{array}{l}\text { Square of the } \\
\text { correlation } \\
\text { coefficient } R^{2}\end{array}$ \\
\hline 873 & 0.0046 & -0.0067 & 0.9977 \\
898 & 0.0103 & 0.0117 & 0.9986 \\
923 & 0.0206 & -0.0121 & 0.9896 \\
948 & 0.0364 & 0.0219 & 0.9973 \\
973 & 0.0582 & 0.107 & 0.9992 \\
\hline
\end{tabular}

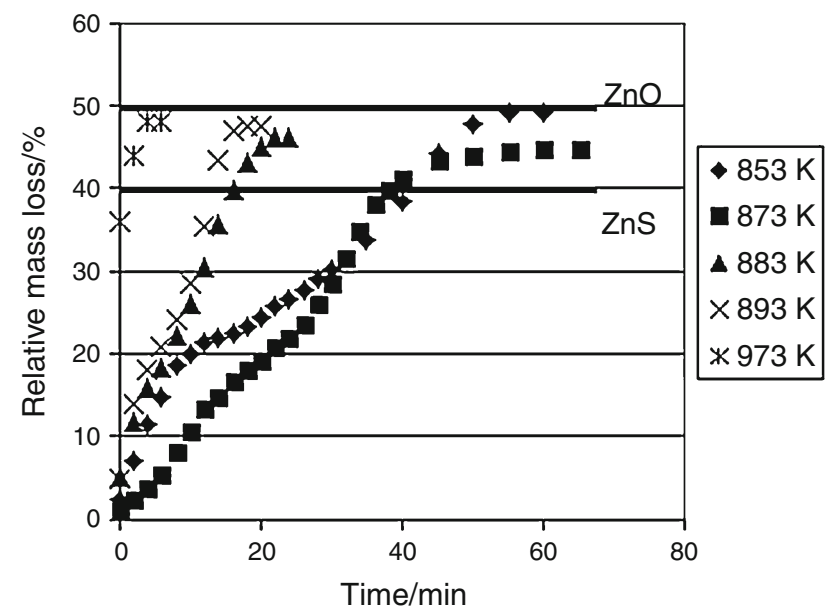

Fig. 7 Change of the relative mass loss of the $\mathrm{ZnSO}_{4}$ sample during the process of reduction by hydrogen in different temperatures

there are clearly two different rate ranges of processes. Such a situation occurs for all experimental temperatures, although at higher temperatures it is less visible, and also in the graph the results are given from the time when the sample achieves the set temperature. Also the ratio between the components of the reaction products changes depending on the temperature. Participation of zinc sulphide in reduction products was calculated in the same manner as in the reduction of lead sulphate. This relationship as a function of temperature is shown in Fig. 8. Interestingly, similar to the case of lead sulphate reduction, a maximum incidence of sulphide product at temperature $873 \mathrm{~K}$ is observed. Below and above this temperature, the participation of $\mathrm{ZnO}$ in the reaction products increases. This may be caused by the fact that below a temperature of $873 \mathrm{~K}$, the reaction rate of sulphate reduction to sulphide is lower than the rate of the reaction between the sulphide and sulphate, which runs at the phase boundary. At the temperature of $873 \mathrm{~K}$, the reduction reaction rate significantly increases, and above this temperature, the reaction between the sulphide and sulphate dominates.

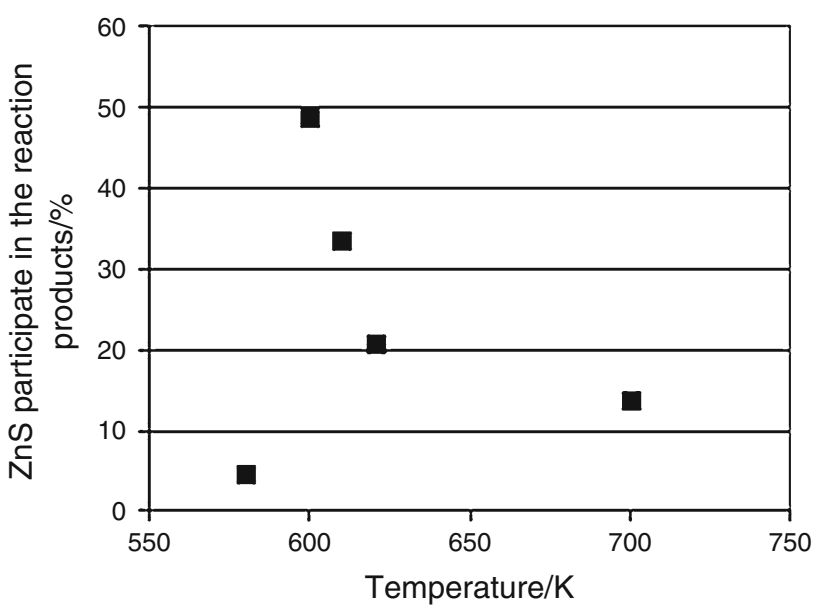

Fig. 8 Relationship between the zinc sulphide content in the products as a function of temperature

\section{Conclusions}

Performed studies and analysis of the results allow us to draw the following conclusions:

1. A process for the reduction of lead sulphate by hydrogen begins at temperatures of about $823 \mathrm{~K}$, and its rate depends strongly on the temperature.

2. The phase composition of products where there are only $\mathrm{PbS}$ and $\mathrm{Pb}$ depends on the process temperature, and maximum content of $\mathrm{PbS}$ at $923 \mathrm{~K}$ is observed.

3. The activation energy of the process is $181 \pm$ $9.5 \mathrm{~kJ} \mathrm{~mol}^{-1}$.

4. The process of zinc sulphate reduction by hydrogen also starts at temperatures of about $823 \mathrm{~K}$, and its rate depends strongly on the temperature.

5. Also in the case of zinc sulphate reduction, phase composition of products where there are only $\mathrm{ZnS}$ and $\mathrm{ZnO}$ depends on the process temperature, and maximum content of $\mathrm{ZnS}$ at a temperature of $873 \mathrm{~K}$ is observed.

Open Access This article is distributed under the terms of the Creative Commons Attribution License which permits any use, distribution, and reproduction in any medium, provided the original author(s) and the source are credited.

\section{References}

1. Plewa J, Steindor J. Kinetics of reduction of magnesium sulfate by carbon oxide. J Therm Anal. 1987;32:1809-20.

2. Habashi F, Mikhail SA, Kim VV. Reduction of sulfates by hydrogen. Can J Chem. 1976;54:3646-50.

3. Habashi F, Mikhail SA. Reduction of binary sulfate mixtures containing $\mathrm{CuSO}_{4}$ by $\mathrm{H}_{2}$. Can J Chem. 1976;54:3651-7.

4. Vijh AK. A thermochemical approach to the gas-phase reduction of metal sulphates. J Mater Sci. 1978;13:2413-7. 
5. Malinowski C, Małecki S, Żołnierczyk D. Reduction of $\mathrm{PbSO}_{4}$ by $\left(\mathrm{CO}+\mathrm{CO}_{2}\right)$ mixture. Thermochim Acta. 2004;423(1-2): 143-8.

6. Malinowski C, Malinowska K. Analysis of the chemical reaction between $\mathrm{PbS}$ and $\mathrm{PbSO}_{4}$ and $\mathrm{ZnSO}_{4}$ on the basis of thermogravimetric investigations (in Polish). ZN AGH Metalurgia i Odlewnictwo Kraków. 1987;1138(109):113-24.
7. Małecki S. Thermogravimetric study of the reduction of basic lead sulphate. J Therm Anal Calorim. 2014;117:1091-5.

8. Tian L, Tahmasebi A, Yu J. An experimental study on thermal decomposition behavior of magnesite. J Therm Anal Calorim. 2014;118:1577-84.

9. Malinowski C. Analysis of the effects of time factors of the oxidation rate of zinc sulphide. Arch Metall. 1983;28:193-207. 